\title{
Design of A Wireless Power Transfer Converter with LC/S Compensation for Electrical Vehicle Battery Charge Applications
}

\author{
Elektrikli Araç Batarya Şarj Uygulamaları için LC/S \\ Kompanzasyonlu Bir Kablosuz Güç Transferi \\ Dönüştürrücüsüinün Tasarımı \\ Sevilay Cetin ${ }^{*} \oplus$, Veli Yenil 2 (1) \\ ${ }^{1}$ Pamukkale University Technology Faculty, Denizli, TURKEY \\ 2 Pamukkale University Cardak Organize Industrial Region Vocational School, Denizli, TURKEY \\ Sorumlu Yazar / Corresponding Author*: scetin@pau.edu.tr \\ Geliş Tarihi / Received: 16.05.2020 Araștırma Makalesi/Research Article \\ Kabul Tarihi / Accepted: 16.11.2020 DOI:10.21205/deufmd.2021236809 \\ Atıfssekli/How to cite: CETIN S., YENIL V. (2021). Design of A Wireless Power Transfer Converter with LC/S Compensation for Electrical \\ Vehicle Battery Charge Applications. DEÜFMD 23(68), 459-468.
}

\begin{abstract}
Wireless power transfer (WPT) has drawn a lot of attention due to its significant advantages such as safety, reliability, weather proof, etc. This paper presents the design methodology of a WPT converter with LC/S compensation topology for electrical vehicle (EV) battery charge applications. The power loss analysis is employed for each component in the WPT converter. The components in the converter are determined based on low power loss and high-power efficiency. The Lithium- ion battery is also preferred in the design due to it's high power density advantage. Since the designed WPT system does not use a dc-dc converter to regulate the output current and voltage, the size and the weight of the overall system can be reduced. Finally, according to given design procedure, a field-electric common simulation of WPT converter is performed with $2 \mathrm{~kW}$ output power while the output voltage is changing between $250 \mathrm{~V}-400 \mathrm{~V}$. The simulated peak efficiency of the converter is obtained around $96.70 \%$ with 0.3 coupling coefficient.
\end{abstract}

Keywords: Electrical Vehicles Battery Charging, Wireless Power Transfer, LC/S Compensation Topolog.

Öz

Kablosuz güç transferi (KGT), güvenilir olması, emniyetli olması ve su geçirmez gibi önemli avantajları ile dikkat çekmektedir. Bu çalışma, elektrikli araç batarya şarj uygulamaları için bir KGT dönüştürücüsünün tasarım metodunu sunmaktadır. KGT dönüştürücüsündeki her bir eleman için güç kayıp analizi verilmiştir. Dönüştürücü elemanları, düşük güç kaybı ve yüksek verim verecek şekilde belirlenmiştir. Aynı zamanda, yüksek güç yoğunluğu avantajı doğrultusunda, tasarımda Lithium-ion batarya tercih edilmiştir. Tasarlanan sistem çıkış akım ve gerilim regülasyonu için bir dc-dc dönüştürücü kullanmadığı için sunulan sistemin boyutları ve ağırlı̆̆ı düşürülebilir. Son olarak, verilen tasarım prosedürüne göre $2 \mathrm{~kW}$ çıkıș gücü ve çıkış gerilimi $250 \mathrm{~V}-400 \mathrm{~V}$ aralığında değișen bir KGT dönüştürücüsünün manyetik-elektrik ortak simülasyonu gerçeklenmiştir. Simülasyon çalışmasında, dönüştürücünün maksimum verimi, 0,3 kuplaj katsayısı ile \%96,70 civarında elde edilmiştir.

Anahtar Kelimeler: Keywords: Elektrikli Araç Batarya Şarjı, Kablosuz Güç Transferi, LC/S Kompanzasyon Topolojisi. 


\section{Introduction}

Wireless power transfer (WPT) technology in battery charging applications has many advantages compared to the traditional plug-in systems. WPT systems are able to transfer energy without using cable. Thus, they provide safe operations for unclean environment [1]-[3]. The high performance Lithium-ion batteries are commonly used as the power supply in EVs, because they have wide range voltage and current rate providing high power density [4][6].

The compensation topologies used in WPT systems have important role in order to provide high efficiency. According to the placement of the resonance capacitor, series- series (SS), seriesparallel (SP), parallel- series (PS) and parallelparallel (PP) compensation topologies can be obtained. Among these topologies, SS and SP are more suitable for WPT system [7]. PS and PP have high turn off current and the impedance of them may be too large, therefore the current will be low for EV charging and the system efficiency decreases. In [8], a comprehensive review of existing compensation topologies is provided based on their basics and advanced features.

Apart from these basic topologies, there are high order compensation topologies such as S/SP [9], LCL [10], [11] and LCC [12]-[17]. In [9], A S/SP topology handles some drawbacks of SS and SP compensation topologies. However, the output power cannot be changed in this topology. An LCL compensation topology providing constant current (CC) output and reducing the conduction losses of power MOSFETs, in the primary side, are proposed in [10], [11]. However, both of them require additional inductors increasing the size of the system. A double-sided LCC compensation topology with its tuning method is introduced in [12]. The proposed topology has the resonant frequency which is independent of the coupling coefficient and load variation. In addition, it achieves ZVS turn-on of power switches. In order to reduce the size of double sided LCC topology and make the system more compact, integrated coil design is proposed in [13], [14]. In [15], high efficiency constant current (CC)/ constant voltage (CV) charge mode allowing minimum frequency variation and zero phase angle (ZPA) is presented with the use of double-sided LCC compensation. In [16], SS and double-sided LCC compensation topologies are compared based on the output power displacements and impacts of the load variation. The characteristics of symmetrical T-type compensation network for LCC compensation topology is analyzed in [17].

Although double- sided LCC compensation topology has a lot of advantages as mentioned above, it requires two resonant inductors and four resonant capacitors that causes larger size of WPT converter [18].

A hybrid LC/S compensation topology which has CC output characteristic is proposed in [19]. Compared to the double-sided LCC topology, the presented LC/S topology has less compensation elements which results in higher efficiency and smaller system size. Besides, LC/S topology achieves both ZPA and ZVS condition for CC mode operation. The tested LC/S converter has a low output power and the airgap between transmitter and receiver coils is $50 \mathrm{~mm}$.

In addition to the compensation topology, coil design is also important part in the design of WPT converter. A comparative review of coil geometries is analyzed in [20], [21]. A circular coil geometry has lower coupling than the other same sized different coil geometries with same sized and airgap. However, circular coil produces same tolerance to misalignment while the direction is changing. Therefore, circular coil is commonly used in static EV battery charging applications.

In this work, LC/S compensation topology is adapted to the EV wireless battery charge application. The main propose of this work is the design methodology of the WPT converter for an $\mathrm{EV}$ battery charger. In the design approach, circular coil geometry is selected for the WPT converter. An analytical power loss analysis is employed to obtain high efficiency design with 2 $\mathrm{kW}$ output power and at the output voltage range varying between $250-400 \mathrm{~V}$. The obtained results are validated by field-electric common simulation work. According to the simulation results, the peak efficiency of the proposed WPT converter is obtained as $96.70 \%$ during the CC charge mode operation.

\section{Design Procedure of The Proposed WPT Converter}

The circuit scheme of the proposed WPT converter using LC/S compensation topology is illustrated in Figure 1. In the transmitter side, $\mathrm{Q}_{1-}$ $\mathrm{Q}_{4}$ represent the inverter switches. In the 
receiver side, $\mathrm{D}_{1}-\mathrm{D}_{4}$ are used to produce $\mathrm{dc}$ output voltage. $L_{p}$ represent the self-inductance of the transmitter coil while Ls represents the receiver coil. The LC/S compensation network composed of $\mathrm{L}_{1}-\mathrm{C}_{1}-\mathrm{C}_{2}$ components. $\mathrm{M}$ is the mutual inductance between coupling coils. $\mathrm{v}_{\mathrm{AB}}$ voltage is produced at the output of the full bridge inverter while $\mathrm{vab}$ is applied to the input of the rectifier. The currents of the transmitter and the receiver coil represent with $i_{p}$ and $i_{s} . C_{o}$ is the output filter capacitor and $R_{0}$ is the equivalent resistance of the battery pack. $V_{\text {in }}$ is applied to the input of the full bridge inverter. $v_{0}$ is produced at the output of the proposed WPT converter. $i_{o}$ is the load current and $\omega$ is the angular switching frequency.

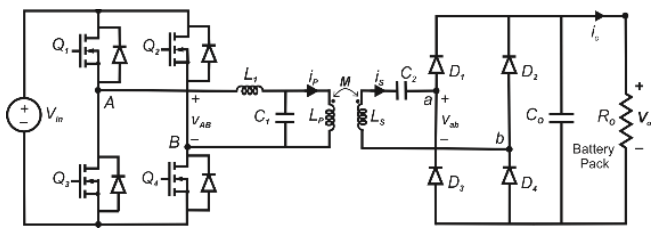

Figure 1. The proposed WPT converter with LC/S compensation.

\subsection{The Output Voltage Regulation}

The dc voltage gain of the WPT converter can be extracted based on mutual inductance model as given in [19], [22]. The mutual inductance model is shown in Figure 2. After the applying Kirchhoff's voltage and current law to the model, the voltage gain can be extracted as

$$
G=\frac{V_{o}}{V_{\text {in }}}=\frac{64 j \omega M R_{o} Z_{C 1}}{\pi^{4} Z_{S}\left(Z_{r}+j \omega L_{P}\right)\left(Z_{C 1}+j \omega L_{1}\right)} .
$$

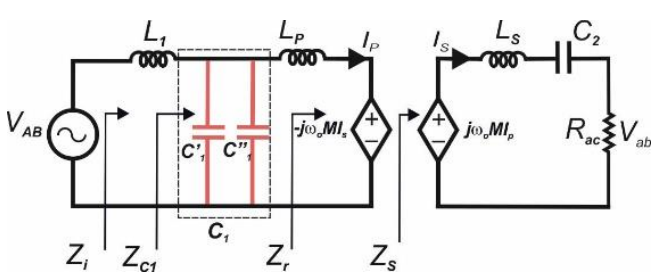

Figure 2. The mutual inductance model of the WPT converter.

Where, $\mathrm{Zs}$ is the secondary side impedance, $\mathrm{Zr}$ is the reflected impedance of $\mathrm{Zs}$. The equivalent impedance of $\mathrm{C}_{1}$, $\mathrm{LP}_{\mathrm{r}}$ and $\mathrm{Z}_{\mathrm{r}}$ is represented by $\mathrm{Z}_{\mathrm{c} 1}$.

The phase angle of the input impedance can be defined as follows:

$$
\varphi_{i}=\frac{180^{\circ}}{\pi} \tan ^{-1} \frac{\operatorname{Im}\left(Z_{i}\right)}{\operatorname{Re}\left(Z_{i}\right)} .
$$

Where $\mathrm{Z}_{\mathrm{i}}$ is the input impedance and defined as

$$
Z_{i}=Z_{C 1}+j \omega L_{1} .
$$

Figure 3 shows the voltage gain (G) of WPT converter with different loads at the resonant frequency, $85 \mathrm{kHz}$. ZPA condition is also provided at the same frequency. The input impedance is changed with the change of the load and the phase angle, $\varphi_{\mathrm{i}}$, of the input impedance is obtained as zero.

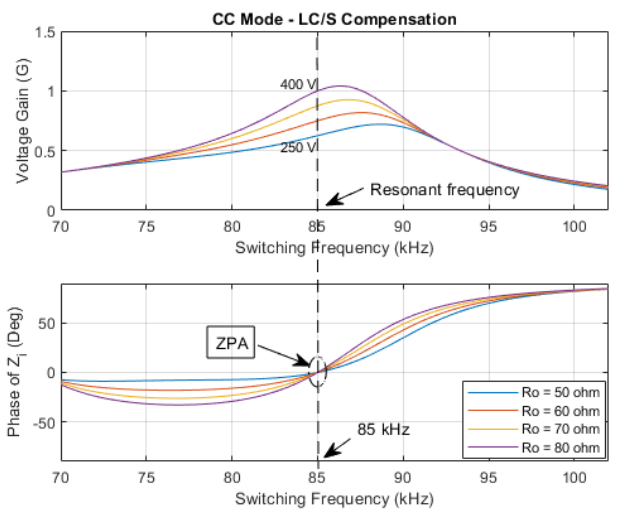

Figure 3. The voltage gain variation of the WPT converter.

\subsection{Power Loss Analysis}

The efficiency is one of the most important parameter for the performance of the WPT system.

The power loss breakdown of the WPT system is composed of conduction loss of rectifier diodes, conduction and switching losses of power MOSFETs, conduction and core losses of the resonant inductor, $\mathrm{L}_{1}$, and conduction loss of coupling coils.

The rectifier diodes in the secondary side are Schottky diodes, therefore their reverse recovery power loss can be neglected.

The conduction loss of the diode bridge can be calculated as below

$$
P_{\text {bridge }}=4 I_{o-a v g} V_{f}
$$


Where, $I_{\text {-avg }}$ is the average value of output current, $V_{f}$ is the forward voltage drop of the rectifier diodes.

Since the WPT converter with LC/S compensation achieves ZVS, the turn on switching loss is neglected for the power MOSFETs. Therefore, only turn off switching losses are calculated as below:

$$
P_{\text {Sw-MOSFET }}=\frac{1}{2} V_{i n} I_{s w-o f f} t_{f} f_{s w} .
$$

Where $f_{s w}$ represents switching frequency, $I_{s w \text {-off }}$ is the turn-off current of the switches, $V_{i n}$ is the dc input voltage, $t_{f}$ is the falling time of the MOSFETs obtaining from its datasheet.

The conduction losses can be calculated as

$$
P_{\text {cond.-MOSFET }}=4 I_{\text {SW-RMS }}{ }^{2} R_{D S-o n} .
$$

Where $I_{S w-R M S}$ and RDS-on are the RMS value of the current flowing through the power MOSFET and turn on resistance of a power MOSFET, respectively.

The conduction power losses of the transmitter and the receiver coils can be written as

$$
\begin{aligned}
& P_{\text {cond.Transmitter }}=I_{P-R M S}{ }^{2} R_{\text {coil }} \\
& P_{\text {cond_-Receiver }}=I_{S-R M S}{ }^{2} R_{\text {coil }} .
\end{aligned}
$$

Where, IP-RMS and IS-RMS are the RMS value of the current flowing in the transmitter and receiver coils, respectively. Both coils are designed as identical and $R_{\text {coil }}$ represents the dc resistance of a circular coil. The ac resistance of the coils is omitted with the use of multiple litz wire. Because any ferrite material is not used in this work, core loss is omitted for the two-circular coils.

The core loss of the resonant inductor, $L_{1}$, can be calculated by a Steinmetz equation, which is written as follows:

$$
P_{\text {core- } L_{1}}=K f_{s w}^{\alpha} B_{m}^{\beta} V .
$$

Where $K, \beta, \alpha$ are determined by curve fitting and $V$ is the core volume. $\mathrm{Bm}_{\mathrm{m}}$ is the maximum flux density in the core of L1.

The maximum flux density of $L_{1}$ is written as

$$
B_{\max -L_{1}}=\frac{L_{1} \cdot I_{L 1-\max }}{N_{L} \cdot A_{L 1}} .
$$

Where $\mathrm{N}_{\mathrm{L}}$ is the number of turns, $\mathrm{A}_{\mathrm{L} 1}$ is the core cross sectional area and $I_{L 1-\max }$ is the maximum current of $L_{1}$.

The conduction loss of $\mathrm{L}_{1}$ is calculated with same principle applied to circular coils. It can be written as

$$
P_{\text {cond.-L1 }}=I_{L 1-R M S}^{2} R_{L 1} \text {. }
$$

Where, $I_{L 1-R M S}$ and $R_{L 1}$ are the RMS current and dc resistance of the resonant inductor, respectively.

The total power loss of $\mathrm{L}_{1}$ inductor can be minimized with the optimal determination of the core and conduction losses. A magnetic core with larger volume can reduce the core loss but results in longer turns increasing dc resistance and conduction loss of the coil. Therefore, optimum loss can be determined at the point where the conduction and core losses are close each other.

Dielectric losses of the compensation capacitors are determined with

$$
P_{C 1, C 2}=\frac{\tan (\delta)}{2 \pi f_{s W}}\left(\frac{I_{C_{1}-R M S}{ }^{2}}{C_{1}}+\frac{I_{C_{2}-R M S}{ }^{2}}{C_{2}}\right) .
$$

Where, $I_{C 1-R M S}$ and $I_{C 2-R M S}$ are the RMS values of the capacitor's ripple current, $\tan (\delta)$ is the loss factor [23].

The voltage stress of the power MOSFET is limited by the input voltage while the current stress is determined according to the maximum current value of the resonant tank. In addition, low turn on resistance and small output capacitance of MOSFETs are also took into consideration. For the rectifier diodes, Schottky diodes can be preferred due to their approximately zero reverse recovery power loss. The voltage stress of the rectifier diodes is equal to the output voltage and their current stress is limited by the maximum value of the current flowing through the receiver coil.

Finally, the efficiency of the WPT converter can be defined as 


$$
\eta=\frac{P_{o}}{P_{o}+P_{\text {Loss-total }}} .
$$

$P_{o}$ is the output power obtained from the battery side and can be defined as follows:

$$
P_{o}=V_{o} \times I_{o} .
$$

$P_{\text {Loss-total }}$ represents the total power loss of the WPT converter and it can be defined as

$$
\begin{aligned}
P_{\text {Loss-total }} & =P_{\text {sw-MOSFET }}+P_{\text {cond-MOSFET }} \\
& +P_{\text {cond.-Transmitter }}+P_{\text {cond.-Receiver }} . \\
& +P_{\text {core- } L_{1}}+P_{\text {cond.-L1 }}+P_{C 1, C 2 .} .
\end{aligned}
$$

\section{Design Case}

Design case of the WPT converter includes magnetic design, determination of the LC/S compensation components and the other power stage components. In the design case, the output voltage is assumed to be changed between 250 and $400 \mathrm{~V}$, the maximum power is $2 \mathrm{~kW}$, and coupling coefficient $(\mathrm{k})$ obtained from airgap between transmitter and receiver coils is 0.3. The statement of the coupling coefficient can be given as follows:

$$
k=\frac{M}{\sqrt{L_{P} L_{S}}} .
$$

The coupling coefficient decreases while the air gap between the transmitter and the receiver coils increases.

At the load side of the WPT converter, it is assumed that 108 Lithium-ion battery cells are series connected to achieve targeted output voltage range. The switching frequency in CC mode is selected as $85 \mathrm{kHz}$

The components of the LC/S compensation are employed in terms of high efficiency according to design procedure given in [19]. $C_{1}$ resonates with $\mathrm{L}_{1}$ and LP so it's selection is critical to achieve ZPA. $\mathrm{C}_{1}$ is divided into two parts as $\mathrm{C}_{1}{ }^{\prime}$ and $\mathrm{C}_{1}$ ", given as follows.

$$
C_{1}=C_{1}{ }^{\prime}+C_{1}{ }^{\prime} .
$$

$\mathrm{C}_{1}$ ' resonates with $\mathrm{L}_{1}$ and their resonant frequency is equal to the frequency of $V_{A B}$ produced by the inverter, to obtain sinusoidal and amplitude constant output current from the $\mathrm{L}_{1}-\mathrm{C}_{1}{ }^{\prime}$ resonant tank. Similarly, $\mathrm{C}_{1}{ }^{\prime \prime}$ resonates with $L_{P}$ at the same frequency. The output current of $\mathrm{L}_{1}-\mathrm{C}_{1}$ ' resonant tank is also the input current of $\mathrm{C}_{1}{ }^{\prime}$-Lp resonant tank. Thus, the output of the $\mathrm{C}_{1}$ "'-Lp resonant tank is also sinusoidal [19]. In the presented design case, $\mathrm{C}_{1}{ }^{\prime}$ is approximately half of the $\mathrm{C}_{1}$ " according to determined $L_{1}$ and $L_{p}$ values.

$\mathrm{L}_{1}$ is determined according to the output current of the WPT converter. $\mathrm{C}_{2}$ is also selected to achieve the ZPA in CC mode, it's determination is given as

$$
C_{2}=\frac{L_{P} C_{1}{ }^{\prime}}{\omega_{0}{ }^{2}\left(L_{S} L_{P} C_{1}{ }^{\prime}-M^{2} C_{1}\right)} .
$$

Where $\omega_{0}$ represents the angular resonance frequency.

The wireless coil design is important part in WPT battery charger system. Circular coils are widely used in EV battery charging applications. Circular coils have same tolerance to the misalignment in all directions and easy to design [20]. Therefore, the circular coil structure is selected in this work.

In the inductive power transfer applications, coupling coefficient is low and its range effectively 0.1-0.3 due to its loosely coupled characteristic. In order to achieve high efficiency, high $\mathrm{k}$ is desirable [24]. Besides, in order to avoid big stress on $L_{P}$ and $C_{1}$, the inductance of transmitter and receiver coil should be relatively large [19]. Recently, SAE J2954 standard is determined the switching frequency range between $81.38 \mathrm{kHz}$ - $90 \mathrm{kHz}$ for WPT charging. If the mutual inductance has a larger value, it causes to higher switching frequency to regulate the output voltage. In contrary, a smaller mutual inductance leads to lower switching frequency [25]. Thus, the required switching frequency values may be out of the standard range established by SAE. Therefore, taking into consideration all above conditions and power transfer capability, LP and Ls are selected as 210 $\mu \mathrm{H}$. The coupling coefficient is determined as 0.3 to provide required mutual inductance and the frequency range allowing by SAE. In the WPT charging of EV, the air gap usually changes from $25 \mathrm{~cm}$ to $10 \mathrm{~cm}$ [21]. Therefore, in this work, the 
air gap is determined as $10 \mathrm{~cm}$ to ensure 0.3 coupling coefficient.

For the design of circular coils, a magnetic simulation is performed with 3D finite element analysis (FEA) software. The circular coils, modeled with a 3D FEA software, are shown in Figure 4. The conductor diameter of circular coils in 3D Modeling is $4 \mathrm{~mm}$ taking into consideration the flowing current through them. The outer and inner diameters of circular coils are $444 \mathrm{~mm}$ and $280 \mathrm{~mm}$ with $0.1 \mathrm{~mm}$ turn spacing to provide $210 \mu \mathrm{H}$ inductance value. The resistance of the conductors in the 3D modeling is omitted and multiple litz wire (404 leads with $0.1 \mathrm{~mm}$ diameter) is used for the loss calculation.

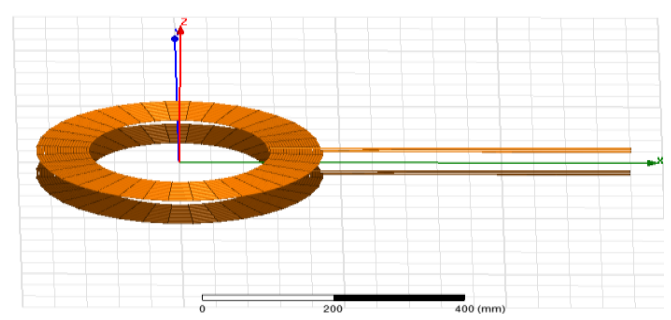

Figure 4. The modeled circular coils with 3D FEA software.

The design of the $\mathrm{L}_{1}$ resonant inductor requires core material with minimum power loss characteristic at the operation frequency. The core shape, window area and core volume should ensure that saturation which is not occurred at the operating flux density. EPCOS(TDK) E55/28/25 core is selected to guarantee the safe operation region.

The determined designed parameters of WPT converter with LC/S compensation and the other design specifications are listed in Table 1 and Table 2.

The calculated loss distribution, according to the presented power loss analysis, while the output voltage is $400 \mathrm{~V}$ and the output current is $5 \mathrm{~A}$, is shown in Figure 5. With respect to analysis result, the losses of circular coils account for the largest power loss compared to the others. The conduction loss of the rectifier diodes is also dominated into total power loss of the WPT converter with LC/S compensation. The core losse can be calculated with the help of datasheet parameters of N87 ferrite material.
Tablo 1. The Design Specifications of WPT Converter for EV Battery Charger.

\begin{tabular}{lll}
\hline \multicolumn{2}{l}{ Paramaters } & Values \\
\hline $\mathrm{P}_{\mathrm{o}}$ & Output power & $2 \mathrm{~kW}$ \\
$\mathrm{~V}_{\text {in }}$ & Input dc voltage & $400 \mathrm{~V}$ \\
$\mathrm{~V}_{\mathrm{o}}$ & Output dc voltage & $250-400 \mathrm{~V}$ \\
$\mathrm{I}_{\mathrm{o}}$ & Charge current & $5 \mathrm{~A}$ \\
$\mathrm{f}_{\mathrm{o}}$ & Resonant frequency & $85 \mathrm{kHz}$ \\
$\mathrm{k}$ & Coupling coefficient & 0.3 \\
\hline
\end{tabular}

Tablo 2. The Determined Design Parameters of WPT Converter for EV Battery Charger.

\begin{tabular}{|c|c|}
\hline Parameters & Values \\
\hline \multirow[t]{2}{*}{$\mathrm{L}_{1}$} & $405 \mu \mathrm{H}-\mathrm{EPCOS}(\mathrm{TDK}) 2 \times E 55 / 28 / 25$ \\
\hline & $\begin{array}{l}37 \text { turns of Litz wire ( } 404 \text { leads with } 0.1 \\
\text { mm diameter), } \mathrm{R}_{\mathrm{L} 1}=0.0425 \Omega\end{array}$ \\
\hline Lp-Ls & $\begin{array}{l}210 \mu \mathrm{H}-\mathrm{Np}=20 \text { turns of multiple Litz } \\
\text { wire ( } 404 \text { leads with } 0.1 \mathrm{~mm} \text { diameter), } \\
\mathrm{R}_{\text {coil }}=0.17 \Omega\end{array}$ \\
\hline $\mathrm{C}_{1}$ & $25.2 \mathrm{nF}$ \\
\hline $\mathrm{C}_{2}$ & $22.5 \mathrm{nF}$ \\
\hline $\mathrm{S}_{1}-\mathrm{S}_{4}$ & C3M0065090D / 900 V- 36 A \\
\hline $\mathrm{D}_{1}-\mathrm{D}_{4}$ & C4D30120D / $1200 \mathrm{~V}-43 \mathrm{~A}$ \\
\hline
\end{tabular}

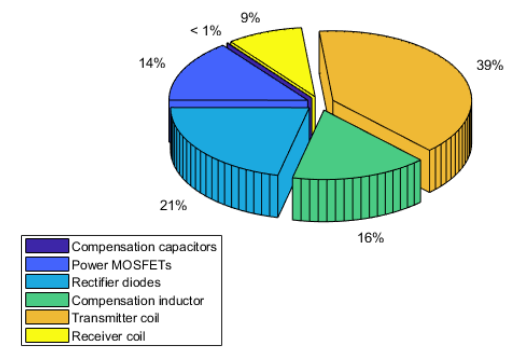

Figure 5. The calculated loss distribution of the WPT converter at full load operation. $V_{0}=400 \mathrm{~V}$, $\mathrm{I}_{\mathrm{o}}=5 \mathrm{~A}$.

The efficiency against the output voltage, and the switching frequency are shown in Figure 6 and 
DEÜ FMD 23(68), 459-468, 2021

Figure 7, when the components listed in Table 2 are used. The peak efficiency of the system is obtained as $96.98 \%$ at the resonance frequency during CC charge mode, at full load condition. The efficieny of WPT converter slightly changes around $96 \%$ duing CC mode. The output voltage is regulating between $250 \mathrm{~V}$ and $400 \mathrm{~V}$ while the load resistance is changing between $50 \Omega$ and 80 $\Omega$. Figure 6 shows the load independent feature of LC/S compensation topology during CC operation mode. The total calculated loss is approximately extracted as $60.7 \mathrm{~W}$ at full load operation.

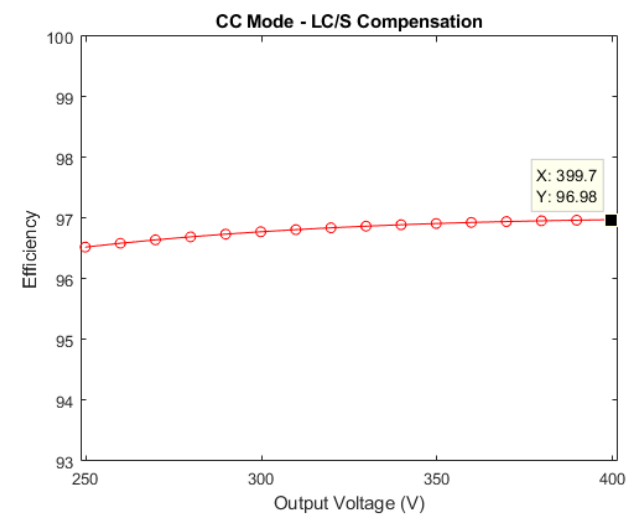

Figure 6. Efficiency of the WPT converter as function of the output voltage.
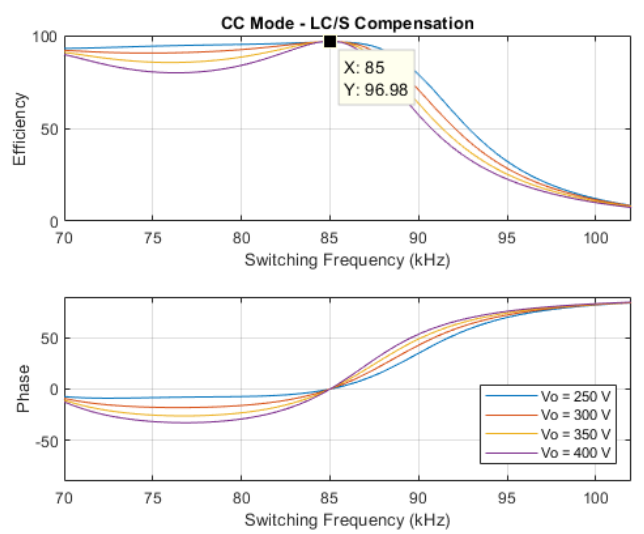

Figure 7. Efficiency of the WPT converter as function of switching frequency.

\section{Simulation Results}

A simulation study is performed to validate the proposed WPT converter with LC/S compensation. For the simulation, 3D fieldelectrical common simulation is used. The simulation work is operated for the specification and parameters listed in Table 1 and Table 2. In the simulation work, a varying resistive load is used in order to simulate the battery behaviour.

The CC mode simulation results are shown in Figure 8 and Figure 9. The preset output current is $5 \mathrm{~A}$. When the Ro changes from $50 \Omega$ to $80 \Omega$, Io is maintained as constant and $V_{o}$ rises from $250 \mathrm{~V}$ to $400 \mathrm{~V}$ which is targeted for the battery charge applications. In this charge mode, the current regulation is provided at $85 \mathrm{kHz}$.

The CV charging mode simulation results are shown in Figure 10 and Figure 11, while the output voltage is regulating at $400 \mathrm{~V}$. When the $\mathrm{R}_{0}$ changes from $80 \Omega$ to $180 \Omega$, Io decreases from $5 \mathrm{~A}$ to $2.2 \mathrm{~A}$ and $\mathrm{V}_{\mathrm{o}}$ is maintained as constant. In this charge mode, voltage regulation is provided between $88.3 \mathrm{kHz}-89.4 \mathrm{kHz}$ switching frequencies. The switching frequency has to be changed to keep the output voltage constant while the load is changing. The required frequency variation is obtained from a closed loop controller built another software. In the controller design, two PI controllers are used to regulate the output current in CC mode and the output voltage in CV mode, respectively. 


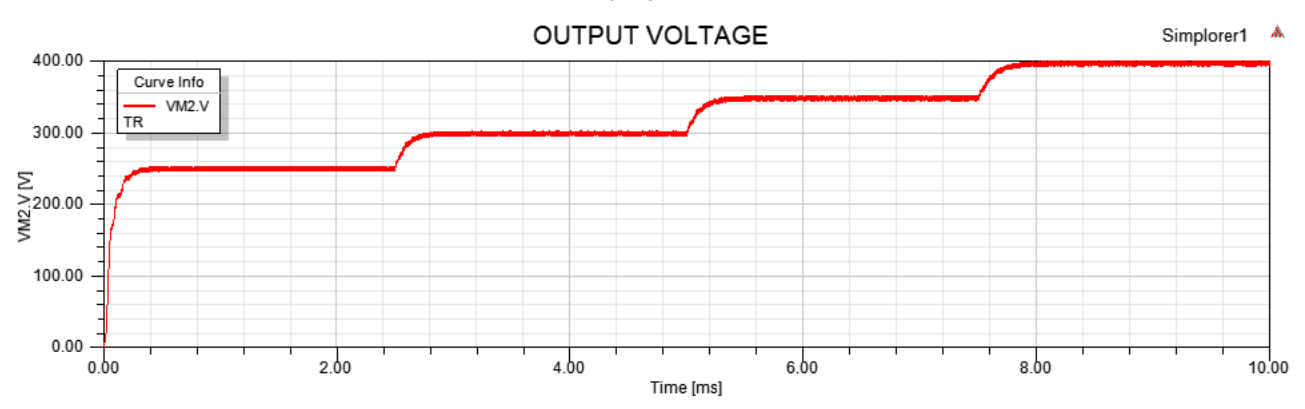

Figure 8. The output voltage variation of WPT converter in CC charge mode.

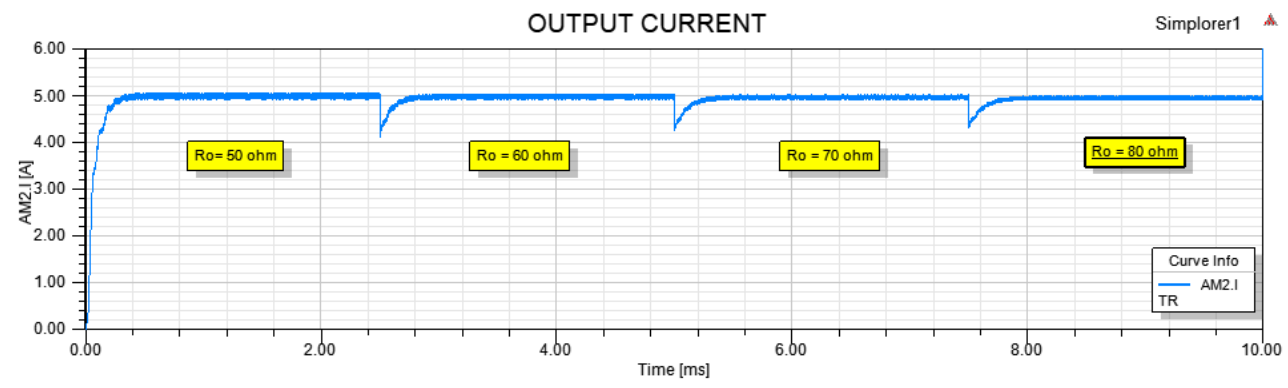

Figure 9. The output current variation of WPT converter in CC charge mode.

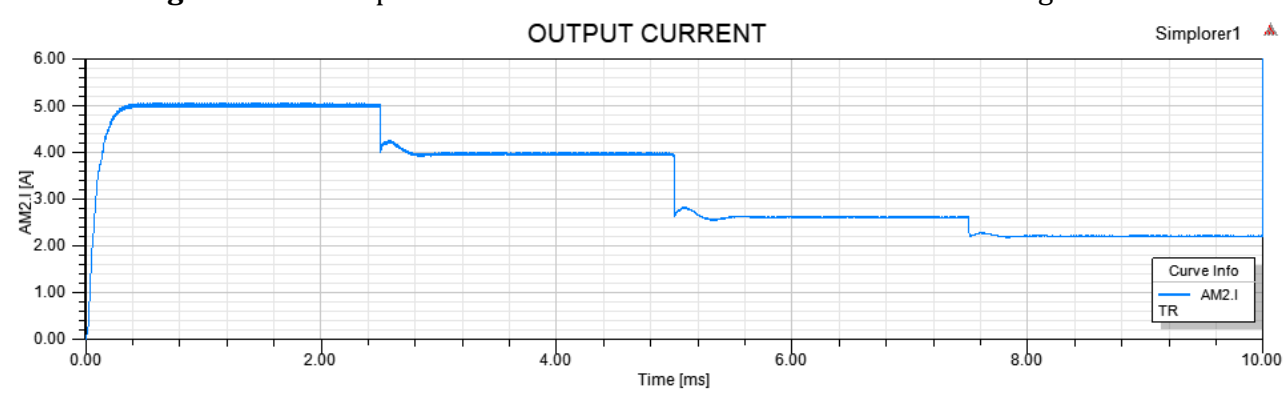

Figure 10. The output current variation of WPT converter in CV charge mode.

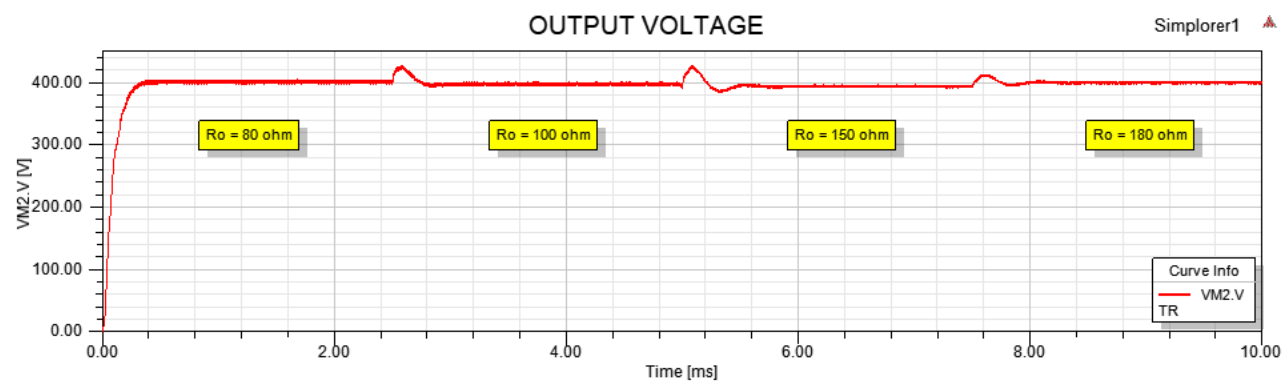

Figure 11. The output voltage variation of WPT converter in CV charge mode.

Figure12 shows the efficiency of the WPT converter at different output voltage during CC charge mode. Figure13 shows the efficiency of the converter during CV charge mode. The peak efficiency is obtained as $96.70 \%$ during the CC charge mode, at $75 \%$ load condition. The efficiency of full load condition is obtained as $96.20 \%$ and this result is very close to the 
analytical result obtained as $96.98 \%$, at full load condition of CC charge mode. According to the obtained results, the efficiency worsens especially at light loads in $\mathrm{CV}$ mode due to failure of ZPA, as given in [22].

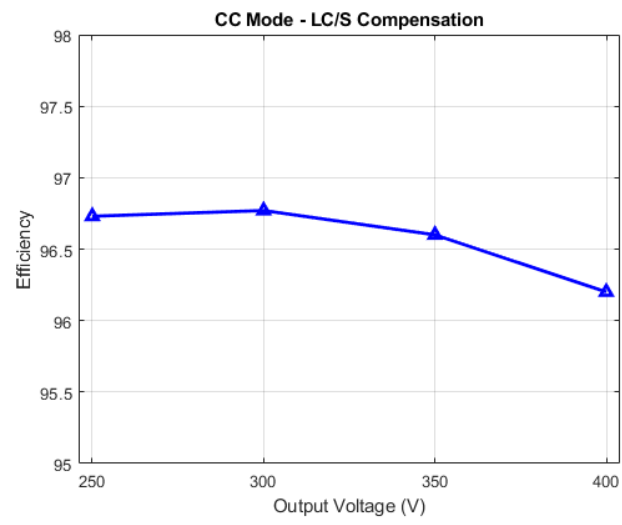

Figure 12. The efficiency variation of WPT converter during CC charge mode.

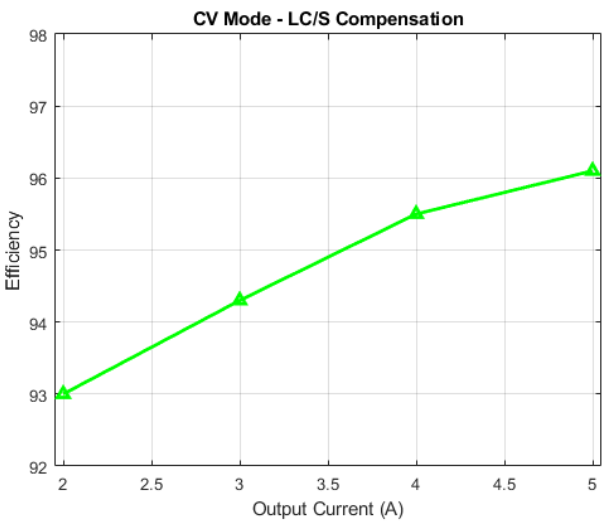

Figure 13. The efficiency variation of WPT converter under the different load condition in $\mathrm{CV}$ mode.

The simulated power loss distribution of WPT converter is shown in Figure 14, while the output voltage is $400 \mathrm{~V}$ and the output current is $5 \mathrm{~A}$. It indicates that the circular coils account for a large proportion of system losses. These results are very close to analytical results.

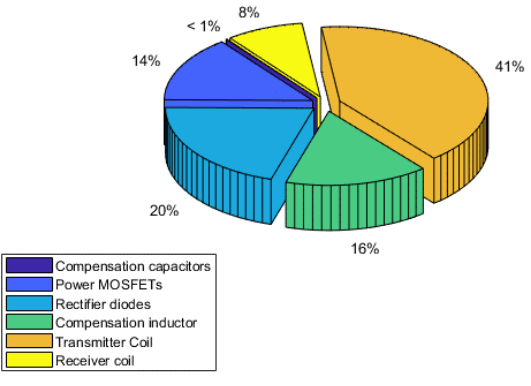

Figure 14. The simulated loss distribution of WPT converter at full load operation. $\mathrm{V}_{0}=400 \mathrm{~V}$, $\mathrm{I}_{\mathrm{o}}=5 \mathrm{~A}$.

\section{Conclusions}

In this paper, design methodology of a WPT converter with LC/S compensation topology for EV battery charge application is presented. The basic principles of LC/S compensation are discussed then the power loss analysis is employed for each power component of the WPT converter. The operation of the proposed WPT converter is validated by a field-electric common simulation. According to simulation result, a WPT converter with LC/S compensation shows that the system is able to transfer $2 \mathrm{~kW}$ with $96.70 \%$ peak efficiency when fully aligned of circular coils.

\section{Acknowledgement}

This work is supported by Pamukkale University under grant number 2020FEBE034.

\section{References}

[1] Li, S., Mi, C.C. 2015. Wireless Power Transfer for Electric Vehicle Applications, IEEE Journal of Emerging and Selected Topics in Power Electronics, Vol. 3, pp. 4-17. DOI:10.1109/JESTPE.2014.2319453.

[2] Zhang, Z., Pang, H., Georgiadis, A., Cecati, C. 2019. Wireless Power Transfer - An Overview, IEEE Transactions on Industrial Electronics, Vol. 66, pp. 1044-1058. DOI: 10.1109/TIE.2018.2835378.

[3] Zhang, W., Wong, S.C., Tse, C.K. 2014. Design for Efficiency Optimization and Voltage Controllability of Series-Series Compensated Inductive Power Transfer Systems, IEEE Transactions on Power Electronics, Vol. 29, pp. 191- 200. DOI: 10.1109/TPEL.2013.2249112.

[4] Song, K., Li, Z., Jiang, J., Zhu, C. 2018. Constant Current/Voltage Charging Operation for SeriesSeries and Series-Parallel Compensated Wireless Power Transfer Systems Employing Primary Side Controller, IEEE Transactions on Power Electronics, 
DEÜ FMD 23(68), 459-468, 2021

Vol. 33, pp. 8065-8080. DOI 10.1109/TPEL.2017.2767099.

[5] Chen, M., Rinc'on-Mora, G.A. 2006. Accurate, Compact and Power-Efficient Lithium-ion Battery Charger Circuit, IEEE Transactions on Circuits and Systems II, Express Briefs, Vol. 53, pp. 1180-1184. DOI:10.1109/TCSII.2006.883220.

[6] Dearborn, S. 2005. Charging Lithium-ion Batteries for Maximum Run Times, Power Electronics Technology Magazine, Vol. 31, pp. 40-49.

[7] Yao, Y., Wang, Y., Liu, X.., Lin, F., Xu, D.G. 2018. A Novel Parameter Tuning Method for Double-sided LCL Compensated WPT System with Better Comprehensive Performance, IEEE Transactions on Power Electronics, Vol. 33, pp. 8525-8536. DOI:10.1109/TPEL.2017.2778255.

[8] Zhang, W., Mi, C.C. 2016. Compensation Topologies of High-Power Wireless Power Transfer Systems, IEEE Transactions on Vehicular Technology, Vol. 65, pp. 4768-4778. DOI:10.1109/TVT.2015.2454292.

[9] Hou, J., Chen, Q., Wong, S.C., Tse, C.K., Ruan, X. 2015. Analysis and Control of Series/Series-Parallel Compensated Resonant Converter for Contactless Power Transfer, IEEE Journal of Emerging and Selected Topics in Power Electronics, Vol. 3, pp. 124136. DOI:10.1109/JESTPE.2014.2336811.

[10] Liu, C., Ge, S., Guo, Y., Li, H., Cai, G. 2016. Double-LCL Resonant Compensation Network for Electric Vehicles Wireless Power Transfer: Experimental Study and Analysis. IET Power Electronics, Vol. 9, pp 2262-2270. DOI:10.1049/iet-pel.2015.0186.

[11] Wang, C. S., Covic, G.A., Stielau, O.H. 2004. Investigating An LCL Load Resonant Inverter for Inductive Power Transfer Applications, IEEE Transactions on Power Electronics, Vol. 19, pp. 9951002. DOI:10.1109/TPEL.2004.830098.

[12] Li, S., Li, W., Deng, J., Nguyen, T.D., Mi, C.C. 2015. A Double-Sided LCC Compensation Network and Its Tuning Method for Wireless Power Transfer, IEEE Transactions on Vehicular Technology, Vol. 64, pp. 2261-2273. DOI:10.1109/TVT.2014.2347006.

[13] Kan, T., Nguyen, T. D., Wjite, J.C., Malhan, R.K., Mi, C.C 2017. A New Integration Method for An Electric Vehicle Wireless Charging System Using LCC Compensation Topology, IEEE Transactions on Power Electronics. Vol. 32, pp. 1638-1650. DOI:10.1109/TPEL.2016.2552060.

[14] Kan, T., Lu, F., Nguyen, T.D., Mercier, P.P., Mi, C.C. 2018. Integrated Coil Design for EV Wireless Charging Systems Using LCC Compensation Topology. IEEE Transactions on Power Electronics. Vol. 33, pp. 9231-9241. DOI:10.1109/TPEL.2018.2794448.

[15] Vu, V.B., Doan, V.T., Pham, V.L., Choi, W.J. 2016. A New Method to Implement the Constant CurrentConstant Voltage Charge of The Inductive Power Transfer System for Electric Vehicle Applications. IEEE Transp. Electrification Conference Expo, (ITEC Asia-Pacific), 1-4 June, Busan / South Korea, 449453.

[16] Li, W., Zhao, H., Deng, J., Li, S., Mi, C.C. 2016. Comparison Study on SS and Double-Sided LCC Compensation Topologies for EV/PHEV Wireless Chargers, IEEE Transactions on Vehicular
Technology, Vol. 65, pp. 4429-4439, DOI:10.1109/TVT.2015.2479938.

[17] Zhu, Q., Wang, L., Guo, Y., Liao, C., Li, F. 2016. Applying LCC Compensation Network to Dynamic Wireless EV Charging System, IEEE Transactions on Industrial Electronics, Vol. 63, pp. 6557-6567, DOI:10.1109/TIE.2016.2529561.

[18] Wang, Y., Yao, Y., Liu, X., Xu, D. 2017. S/CLC Compensation Topology Analysis and Circular Coil Design for Wireless Power Transfer, IEEE Transactions on Transportaion Electrification, Vol. 3, pp. 496-507, DOI: 10.1109/TTE.2017.2651067.

[19] Wang, Y., Yao, Y., Liu, X., Xu, D. G., Cai, L. 2018. An LC/S Compensation Topology and Coil Design Technique for Wireless Power Transfer, IEEE Transactions on Power Electronics, Vol. 33, pp. 2007-2025, DOI:10.1109/TPEL.2017.2698002.

[20] Aditya, K., Sood, V. K., Williamson, S.S. 2017. Magnetic Characterization of Unsymmetrical Coil Pairs Using Archimedean Spirals for Wider Misalignment Tolerance in IPT Systems, IEEE Transactions on Transportation Electrification, Vol. 3, pp. 454-463, DOI:10.1109/TTE.2017.2673847.

[21] Ahmad, A., Alam, M.S., Chabaan, R. 2018. A Comprehensive Review of Wireless Charging Technologies for Electric Vehicles, IEEE Transactions on Transportation Electrificcation, Vol. 4, pp. 38-63, DOI:10.1109/TTE.2017.2771619.

[22] Cetin, S., Yenil V. First Published 22 June 2020 Performance Evaluation of Constant Current and Constant Voltage Charge Control Modes of An Inductive Power Transfer Circuit with Double-Sided LCC and LC/S Compensations for Electrical Vehicle Battery Charge Applications, Transactions of the Institute of Measurement and Control, DOI:10.1177/0142331220932438.

[23] Badstuebner, U., Biela, J., Kolar, J.W. 2010. Design of An 99\%-Efficient, 5kW, Phase-Shift PWM DC-DC Converter for Telecom Applications, Twenty-Fifth Annual IEEE Applied Power Electronics Conference and Exposition (APEC), 21-25 February, ), Palm Springs, CA /USA, 773-780.

[24] Kim, M., Joo, D. M., Lee, B. K. 2019. Design and Control of Inductive Power Transfer System for Electric Vehicles Considering Wide Variation of Output Voltage and Coupling Coefficient, IEEE Transactions on Power Electronics, Vol. 34, pp. 1197-1208, DOI: 10.1109/TPEL.2018.2835161.

[25] Liu, N., Habetler, T. G. 2015. Design of a Universal Inductive Charger for Multiple Electric Vehicle Models, IEEE Transactions on Power Electronics, Vol. 30, pp. 4894-4905. DOI:10.1109/TPEL.2015.2394734. 